\title{
Platinum and Gold Catalysis: à la Carte Hydroamination of Terminal Activated Allenes with Azoles
}

\author{
José Miguel Alonso:[a] and María Paz Muñoz ${ }^{*}[a]$.
}

[a] School of Chemistry, University of East Anglia, Norwich NR4 7TJ (UK).

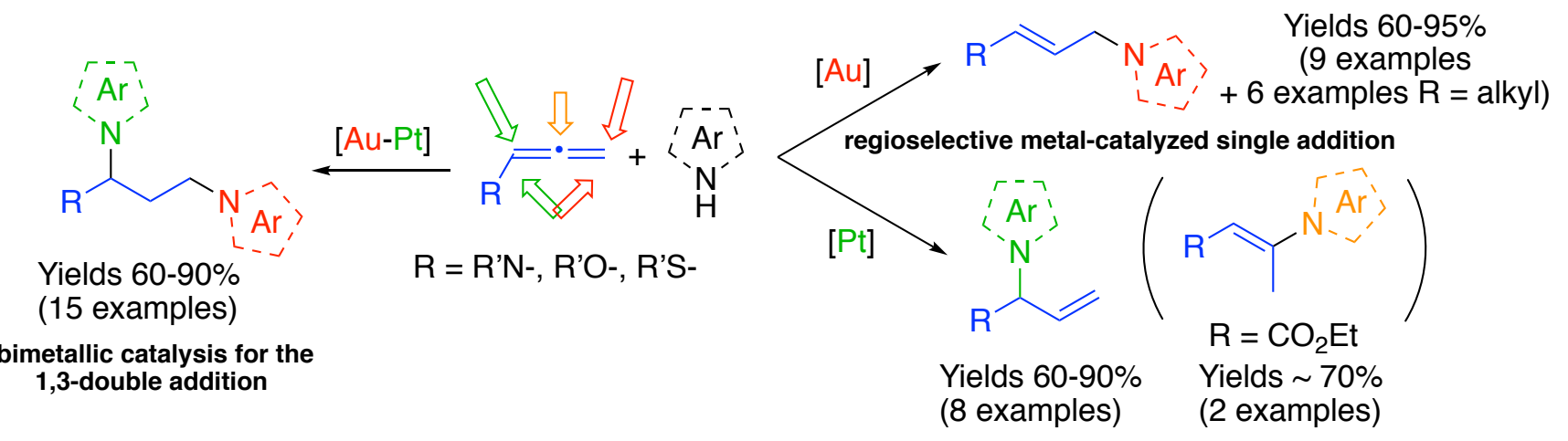

\begin{abstract}
Nucleophilic additions to allenes catalyzed by transition metals represent a powerful tool to get selective access to diverse structures with numerous applications. Reported here is a straightforward methodology to achieve selective addition of azoles to the proximal or distal carbon of activated allenes depending on the catalyst used, unravelling a gold-platinum bimetallic catalysis approach for the 1,3-double addition of azoles to activated allenes to give 1,3-bisazole derivatives, important scaffold in medicinal and organometallic chemistry.
\end{abstract}

Nucleophilic addition onto transition metal-activated $\mathrm{C}=\mathrm{C}$ bonds represents an efficient methodology to gain access to a wide variety of functionalized molecules in an atom economic manner. ${ }^{1}$ On this matter, allenes provide diverse advantages compared to alkenes or alkynes, as they present three reaction sites, and they offer the possibility to modulate the electrophilicity of each one of them. The reactivity pattern for any nucleophilic attack onto allene systems depends on the catalyst and the electronic nature of the allene. Distal, proximal and central carbon intermolecular single addition to yield derivatives 2-4 (Scheme 1a, right) have been described with a variety of allenes, nucleophiles and metals, where gold has been widely explored. ${ }^{2}$ In the case of activated allenes the regioselectivity generally depends on the heteroatom present. For example, alkoxyallenes mostly favor the proximal attack to form analogues $3,{ }^{3}$ while the most common reactivity of allenamides is the addition to the distal carbon to form derivatives $2 .{ }^{4}$ The Pt-catalyzed double distal addition of $C$ - and $O$-based nucleophiles to simple allenes has been described to generate adducts 5 (Scheme 1a, left). ${ }^{5}$ The Au-catalyzed double distalproximal addition to allenamides has been reported in a single example with 2-methylfuran as nucleophile in moderate yield, ${ }^{4 d}$ and with phenol/allyltrimethylsilane to give adducts 6 (Scheme 1a, left). ${ }^{6}$ There is one reported example of the Aucatalyzed double addition of thiols to the central carbon of aromatic allenes to give compounds 7 (Scheme 1a, left). ${ }^{7}$

Among the transformations including allenes and nucleophiles, metal-catalyzed intermolecular hydroamination of al- lenes are the more scarcely reported. ${ }^{8}$ In particular, addition of azoles to allenes represents a powerful tool to generate highly heteroatom-enriched scaffolds with multiple applications in medicinal ${ }^{9}$ and organometallic chemistry. ${ }^{10}$ However, it has been limited so far to the use of Rh with alkyl allenes ${ }^{11 \mathrm{a}}$ and Pd with alkoxyallenes ${ }^{12}$ towards the proximal addition in both cases to generate adducts of type 3 (Scheme 1b), with no examples of addition of azoles to any other positions of the allene reported to date under any metal catalyst.

In recent years, bimetallic catalysis has appeared as a powerful tool to achieve challenging transformations. ${ }^{13}$ In many of them, gold is used as one of the catalysts in combination with another metal. ${ }^{14}$ In the context of allene chemistry, Au-Pd dual catalysis has been reported in the reaction of allenoates to form butenolides. ${ }^{15}$ We have recently reported a dual $\mathrm{Au}-\mathrm{Pt}$ strategy for the reaction of heteroarylallenes in the reaction with heteroaromatic nucleophiles, showing unprecedented reactivity not observed previously with single catalysis strategies. ${ }^{16}$

In this work, we report the effect of gold and platinum catalysis on the hydroamination of activated terminal activated allenes with azoles, unravelling a regioselective à la carte addition of azoles to give the products of the single addition, 2-4 depending on the single catalyst employed, and a novel bimetallic catalysis strategy for the double addition of azoles, to furnish 1,3-bisazole derivatives 6 (Scheme 1c).

Scheme 1. Previous reactivity pattern and present work. 

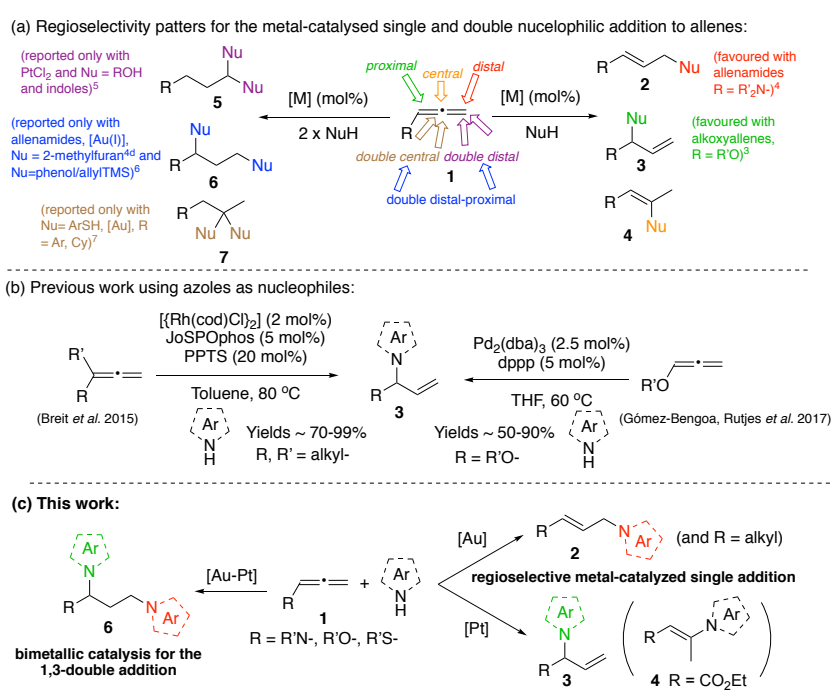

Reaction of allenylsulfonamide $\mathbf{1 A}$ in the presence of 1 equiv. of pyrazole as nucleophile under $\mathrm{Au}(\mathrm{I})$ catalysis slowly generated distal addition allyl derivative $\mathbf{2} \mathbf{A a}$, in line with other Aucatalyzed nucleophilic additions to allenamides, ${ }^{4}$ but showing opposite and complementary regioselectivity to the previously described with $\mathrm{Rh}$ or Pd catalysts. Microwave irradiation at $100{ }^{\circ} \mathrm{C}$ decreased the reaction time to $30 \mathrm{~min}$, providing $2 \mathrm{Aa}$ in quantitative yield (Scheme 2). The scope was extended to different allenamides (1B, 1F, 1G). Interestingly, alkoxyallenes (1C) that generally favor proximal addition ${ }^{3}$ also gave products $2 .{ }^{17}$ Phenylthioallene (1D) and $N$-indolylallene (1E) displayed the same regioselectivity. Different azoles were tested giving complete conversions and good yields.

Scheme 2. Au-catalyzed distal addition of azoles to allenes.

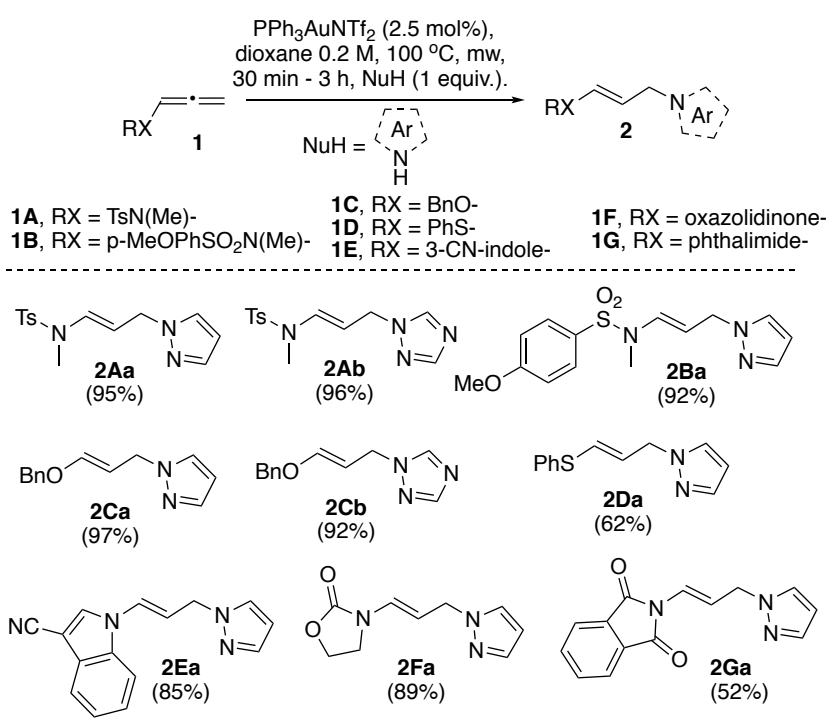

Remarkably, when $\mathrm{PtCl}_{2}$ was used under the same optimized conditions as for $\mathrm{Au}(\mathrm{I})$ catalysis, the reaction of allenylsulfonamide $\mathbf{1 A}$ gave isomer $\mathbf{3 A a}$ as a single product in good yield (Scheme 3 ) in an unusual regioselectivity for this type of substrates. ${ }^{18}$ Different substituted allenamide (1F), $\mathrm{N}$ indolylallene $(\mathbf{1 E})$ and alkoxyallenes $(\mathbf{1 C}, \mathbf{1 H})^{3}$ showed the same regioselectivity in the presence of $\mathrm{PtCl}_{2}$ and different azoles for the synthesis of allyl adducts of type $\mathbf{3}$ (Scheme 3). ${ }^{19}$
Scheme 3. Pt-catalyzed proximal addition of azoles to allenes.

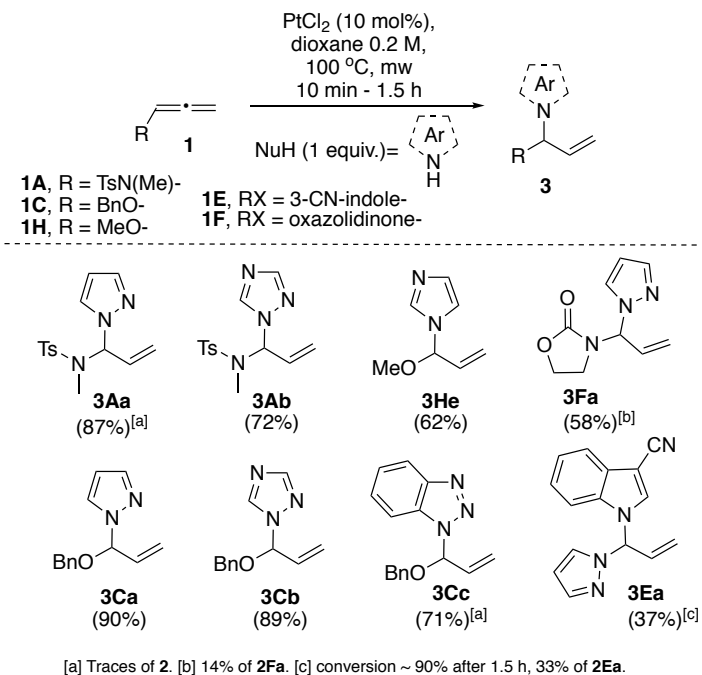

In light of these results, we envisioned the possibility of double addition processes to activated allenes using more powerful bimetallic Au-Pt strategies. To our delight, when allenylsulfonamide 1A was treated with $\mathrm{PtCl}_{2}$ and $\mathrm{PPh}_{3} \mathrm{AuNTf}_{2}$ as catalytic pair, excess of pyrazole as nucleophile, in a dioxane solution at $100{ }^{\circ} \mathrm{C}$ during $1 \mathrm{~h}$ under $\mathrm{mw}$ irradiation, 1,3-bispyrazole derivative 6Aaa was obtained as sole reaction product in good yield, through double distalproximal nucleophilic addition to the allene (Scheme 4). Allenamides $\mathbf{1 B}, \mathbf{1 J}$ and $\mathbf{1 F}$, with different electronic properties, gave adducts $\mathbf{6}$ with the same regioselectivity and excellent yields. Alkoxyallenes $\mathbf{1 C}$ and $\mathbf{1 H}$, phenylthioallene 1D, and $\mathrm{N}$ indolylallenes $\mathbf{1 E}$ and $\mathbf{1 K}$, as well as different azoles, such as benzotriazole or 1,2,4-triazole, gave, under the optimized conditions and with good to excellent yields, a family of adducts 6 showing the attractive 1,3-bisazole motif, a recurring scaffold in medicinal chemistry ${ }^{9}$ and in ligand design for metallic complexes, MOFs and COFs. ${ }^{10}$ Metal complexes of $\mathrm{Zn}^{20}$ and $\mathrm{Ag}^{21}$ using $6 \mathrm{Haa}$ and $6 \mathrm{Hcc}$ were readily synthesized, ${ }^{22}$ which highlights the synthetic utility of these 1,3-bisazoles incorporating an extra functionality and added complexity, not easy to achieve through conventional procedures, in the field of organometallic chemistry.

Interestingly, although $C$-substituted allenes have been reported to react towards the proximal addition of azoles in the presence of $\mathrm{Rh}$ catalysts, ${ }^{11 \mathrm{a}}$ under single $\mathrm{Au}$ or Pt catalysts, cyclohexyl- (1L) and phthalimide- $\mathrm{CH}_{2}$-based $(\mathbf{1 M})$ allenes were unreactive. The combination of $\mathrm{Pt}(\mathrm{II})-\mathrm{Au}(\mathrm{I})$ or $\mathrm{Pt}(\mathrm{II})-$ $\mathrm{Au}$ (III) in a dual catalysis strategy favored the formation of the distal addition products 2 (see compounds $2 \mathbf{L a}, 2 \mathbf{L c}, \mathbf{2 L d}$ and 2Ma-c in the SI), but the double addition was not possible even under harsher conditions with these substrates. ${ }^{22}$

When a deactivated allenoic ester $\mathbf{1 N}$ was used, ${ }^{23}$ isomers $\mathbf{4}$, from the metal-catalyzed conjugated addition of the azole to the central carbon, were obtained as the only isomers with $\mathrm{Au}(\mathrm{I})-\mathrm{Pt}(\mathrm{II})$ bimetallic strategy under more forcing conditions (see compounds $4 \mathbf{N a}, 4 \mathbf{N a}$, 4Nc in the SI). When Au(I)$\mathrm{Pt}(\mathrm{IV})$ was used double addition to the central carbon was also found in the presence of pyrazole to give adduct $7 \mathbf{N a a} .{ }^{22}$ 
Scheme 4. Au-Pt-catalyzed 1,3-bisazole addition to allenes.

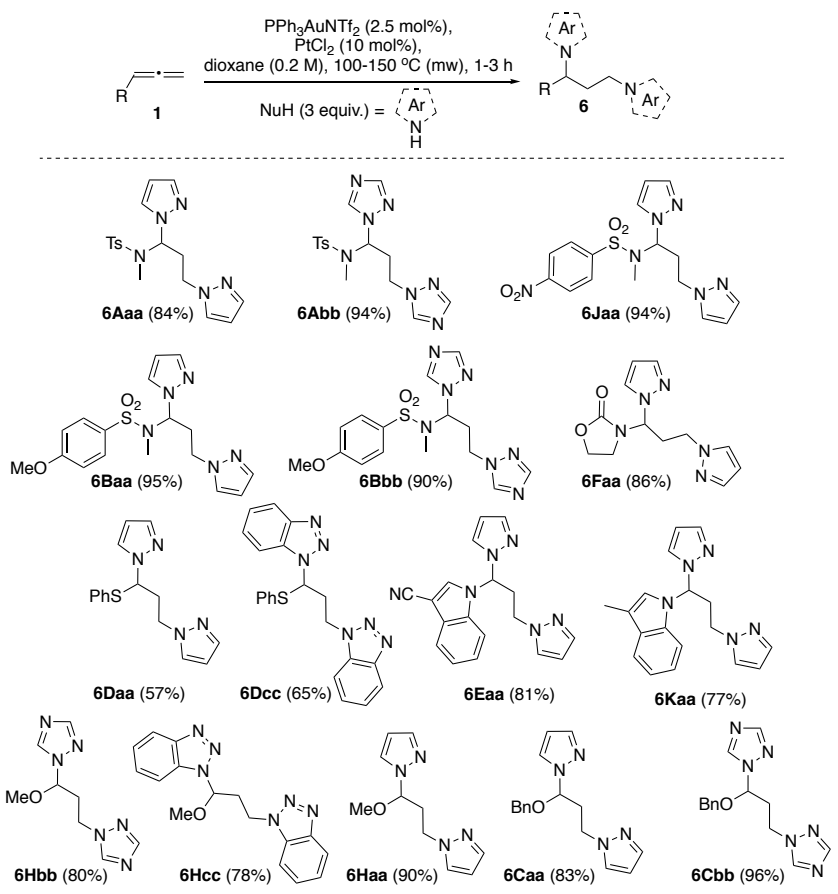

Single catalyst reactions of activated allenes under harsher conditions (excess of azole, longer times, higher temperatures) led to mixtures of isomers $\mathbf{2 - 3}$ and uncompleted conversions towards $\mathbf{6}$, highlighting the need for the bimetallic catalysis to provide 1,3-bisazoles efficiently and pointing to compounds 2 and $\mathbf{3}$ as possible intermediates in the double nucleophilic addition to form $\mathbf{6} .^{22}$ Interestingly, $3 \mathrm{Aa}$ generated $\mathbf{2 A a}$ in every experiment performed (even in the absence of azole), while the reverse process was not observed. This result points to an equilibrium between $\mathbf{3 A a}$ and $\mathbf{2 A a}$, displaced towards $\mathbf{2 A a}$, prior to the second nucleophilic attack to give 6Aaa.

Cross-over experiments in the presence of two different azoles $^{22}$ support the equilibrium between intermediates $\mathbf{3}$ and $\mathbf{2}$ that under the reaction conditions, favors the thermodynamically more stable regioisomer $\mathbf{2}$. Although studies on the goldcatalyzed hydroamination of allenes using hydrazides, ${ }^{24}$ and hydrazines $^{25}$ as nucleophiles, as well as the examples of addition of azoles with $\mathrm{Rh}^{11 \mathrm{a}}$ and $\mathrm{Pd}^{12}$ showed no evidence of isomerization between allyl derivatives, ${ }^{26}$ computational studies on the Au-catalyzed reaction of allenes with oxygen nucleophiles have shown that isomerization between regioisomers 3 and $\mathbf{2}$ can take place during the reaction via a six-membered cyclic gold intermediate in a process with two alcohols involved, to give predominantly the more stable regioisomer $2 .{ }^{27}$ A similar cyclic metallic intermediate involving two azoles could be proposed in our case.

Therefore, a possible reaction mechanism would start with coordination of the metal catalyst to the allene. In the case of activated allenes, the involvement of the heteroatom in the stabilization of the coordinated allene can influence de point of attack (1,2- or 1,4-addition to the proximal or distal carbons). Nucleophilic addition to the proximal carbon atom would generate vinyl-metal intermediate $\mathbf{A}$ that after protonolysis (with acidic protons of the azole) will give $\mathbf{B}$ and $\mathbf{3}$ in a process favored by Pt catalysts, while opposite regioselectivity towards the terminal carbon atom would generate intermediate $\mathbf{A}^{\prime}$ that will give $\mathbf{C}$ and $\mathbf{2}$ in a process favored by Au complex- es (Scheme 5). Isomerization between $\mathbf{B}$ and $\mathbf{C}$ can then occur via intermolecular attack of the second azole to either metalactivated double bond in $\mathbf{B}$ or $\mathbf{C}$ to form a protonated bisazole (bi)metallic intermediate $\mathbf{D}$, resembling the proposed for the reaction with alcohols and gold. ${ }^{27}$ In the presence of the more reactive Au-Pt bimetallic system, intermediate $\mathbf{D}$ could undergo protodemetallation via $\mathrm{S}_{\mathrm{E}} \mathrm{OX}$ process involving protonation of a bimetallic center to form metallic-hydride intermediate $\mathbf{E}$, stabilized by the presence of the second metal. Reductive elimination from E, would form 1,3-bisazole products 6 (Scheme 5). In the presence of single catalysts, formation of the metal-hydride intermediate $\mathbf{E}$, although possible is less favored, ${ }^{28}$ and therefore the reaction stops to give $\mathbf{2}$ or $\mathbf{3}$ depending on the metal employed and only traces of $\mathbf{6}$ in more forcing conditions. The addition of the second azole from 3 and 2 can also be promoted by acid present in the media (excess pyrazole, $\mathrm{Tf}_{2} \mathrm{NH}$ generated in situ), aided by the heteroatom. However, reactions only in the presence of acid are less clean, and decomposition of the product is observed, suggesting this is not the main pathway under bimetallic conditions. $^{29,22}$

Formation of 6Aaa from 1A was quenched under optimized $\mathrm{Au}-\mathrm{Pt}$ conditions and under $\mathrm{Au}$ and Pt single catalyst experiments with excess pyrazole in the presence of TEMPO (10 mol\%), known to trap metal-hydrides. ${ }^{30}$ However, mixtures of 2 and 3 where obtained in the presence of TEMPO in all cases. ${ }^{22}$ Although TEMPO is also known to react with acids, ${ }^{31}$ possibly quenching the second addition, protonolysis of $\mathbf{2}$ and 3 was not affected. Besides, the reaction showed higher conversion towards products $\mathbf{6}$ in the presence of an alternative hydride source $\left(\mathrm{Et}_{3} \mathrm{SiH}\right)$, and gave complex mixtures in the presence of radical initiators (AIBN), supporting that intermediates $\mathbf{2}$ and $\mathbf{3}$ are generated without the involvement of metalhydrides, and the bimetallic hydride as the main pathway for the second azole addition under bimetallic catalysis. ${ }^{22}$

Reaction using $N$-deuterated pyrazole led to final adduct $\boldsymbol{d}_{2}$ 6Aaa showing complete double transference of deuterium from the azole to the central carbon of the allene. Incorporation of the first deuterium can be explained by the protonolysis of $\mathbf{A} / \mathbf{A}^{\prime}$. Incorporation of the second deuterium from the azole in the central carbon would also support metal-hydrides as the main species responsible for the second hydroamination reaction from intermediate D. Stabilization of Au-hydrides ${ }^{32}$ in the presence of a second metal such as Pt has been reported, ${ }^{33}$ which will further support the need for both metals for the more efficient double azole addition observed under bimetallic catalysis.

In conclusion, we have found that from the same starting material and under similar reaction conditions, simply modulating the catalyst used (platinum, gold or both) and the excess of nucleophile, we were able to tune the regioselective addition of azoles to activated allenes to be directed towards the proximal or distal allenic carbon. Remarkably, the combination of gold and platinum as bimetallic system was found to catalyze the double nucleophilic addition of azoles to terminal allenes in high efficiency to give 1,3-diazole derivatives, recurring and attractive scaffolds in catalysis, biological active molecules, and ligands for metal complexes. The divergent reactivity of platinum and gold and the higher efficiency shown towards novel processes in allene chemistry when both metals are used in combination, highlights the importance of 
the understanding of metallic intermediates in synthesis and catalysis for the discovery of new processes.

Scheme 5. Mechanistic proposal for the bimetallic Au-Ptcatalyzed double azole addition to activated allenes.

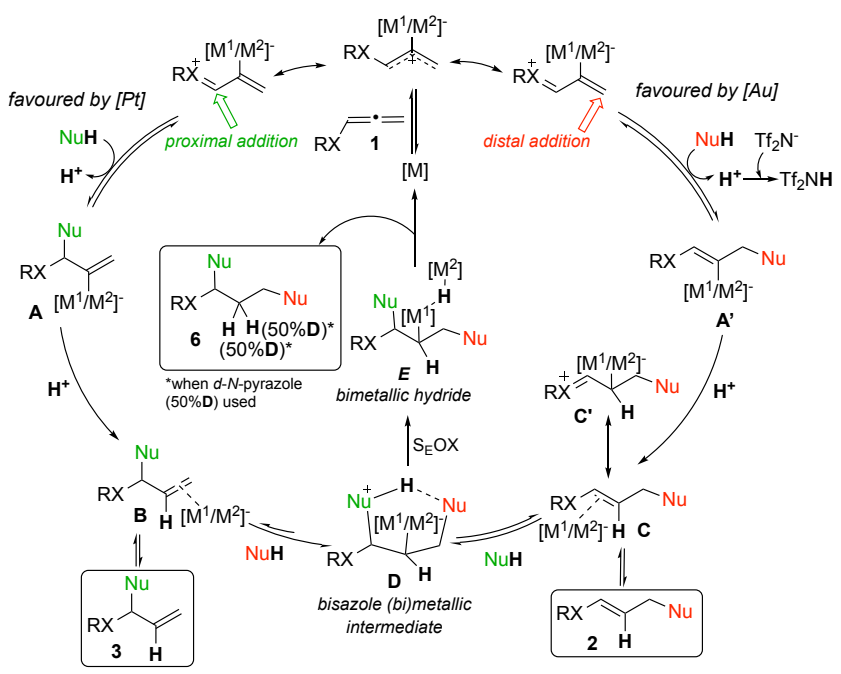

\section{ASSOCIATED CONTENT}

\section{Supporting Information}

The Supporting Information is available free of charge on the ACS Publications website: pdf containing experimental data, full characterization of compounds, details on the mechanistic investigations and copies of the NMR spectra of the new compounds.

\section{AUTHOR INFORMATION}

\section{Corresponding Author}

*E-mail: m.munoz-herranz@uea.ac.uk

\section{Author Contributions}

The manuscript was written through contributions of all authors. / All authors have given approval to the final version of the manuscript. / \$These authors contributed equally.

\section{Funding Sources}

Leverhulme Trust (JMA, RPG-2015-143)

\section{ACKNOWLEDGMENT}

Funding by the University of East Anglia and the Leverhulme Trust (JMA, RPG-2015-143) is gratefully acknowledged. Authors would like to thank Dr Abdul-Sada (University of Sussex) for MS analysis.

\section{REFERENCES}

(1) For selected reviews, see: (a) Patil, N. T.; Kavthe, R. D.; Shinde, V. S. Transition Metal-Catalyzed Addition of C-, N- and ONucleophiles to Unactivated C-C Multiple Bonds. Tetrahedron 2012, 68, 8079-8146. (b) Corma, A.; Leyva-Perez, A.; Sabater. M. J. GoldCatalyzed Carbon-Heteroatom Bond-Forming Reactions. Chem. Rev. 2011, 111, 1657-1712. (c) Liu, C.; Bender, C. F.; Han, X.; Widenhoefer, R. A. Platinum-Catalyzed Hydrofunctionalization of Unactivated Alkenes with Carbon, Nitrogen and Oxygen Nucleophiles. Chem. Commun. 2007, 3607-3618.
(2) For selected reviews, see: (a) Muñoz, M. P. Silver and Platinum-Catalysed Addition of $\mathrm{O}-\mathrm{H}$ and $\mathrm{N}-\mathrm{H}$ Bonds to Allenes. Chem. Soc. Rev. 2014, 43, 3164-3183. (b) Krause, N.; Aksin-Artok, O.; Asikainen, M.; Breker, V.; Deutsch, C.; Erdsack, J.; Fan, H.-T.; Gockel, B.; Minkler, S.; Poonoth, M.; Sawama, Y.; Sawama, Y.; Sun, T.; Voltz, F.; Winter, C. Combined Coinage Metal Catalysis for the Synthesis of Bioactive Molecules. J. Organomet. Chem. 2012, 704, 1-8. (c) Aubert, C.; Fensterbank, L.; Garcia, P.; Malacria, M.; Simonneau, A. Transition Metal Catalyzed Cycloisomerizations of 1,n-Allenynes and -Allenenes. Chem. Rev. 2011, 111, 1954-1993.

(3) For examples of Au-catalyzed proximal alcohol addition to alkoxyallenes to give acetals of type 3, see: (a) Kim, J.; Jeong, W.; Rhee, Y. H. Flexible Tetrahydropyran Synthesis from Homopropargylic Alcohols Using Sequential Pd-Au Catalysis. Org. Lett, 2017, 19, 242-245. (b) Cui, D.-M.; Zheng, Z.-L.; Zhang, C. Gold-Catalyzed Hydroalkoxylation of Alkoxyallenes. J. Org. Chem. 2009, 74, 14261427. For a review on alkoxyallenes reactivity, see: (c) Zimmer, R. Reissig, H.-U. Alkoxyallenes as building blocks for organic synthesis. Chem. Soc. Rev. 2014, 43, 2888-2903.

(4) For selected examples of distal nucleophile addition to allenamides, see: (a) Pirovano, V.; Brambilla, E.; Rizzato, S.; Abbiati, G.; Bozzi, M.; Rossi, E. Gold-Catalyzed Cascade Reactions of $4 \mathrm{H}-$ Furo[3,2-b]indoles with Allenamides: Synthesis of Indolin-3-one Derivatives. J. Org. Chem. 2019, 84, 5150-5166. (b) An, J.; Lombardi, L.; Gilli, S.; Bandini, M. $\mathrm{PPh}_{3}$ AuTFA Catalyzed in the Dearomatization of 2-Naphthols with Allenamides. Org. Lett. 2018, 20, 73807383. (c) Hill, A. W.; Elsegood, M. R. J.; Kimber, M. C. An Intermolecular Hydroamination of Allenamides with Arylamines Catalyzed by Cationic $\mathrm{Au}(\mathrm{I})$ Salts. J. Org. Chem. 2010, 75, 5406-5409. (d) Kimber, M. C. A Facile and Mild Synthesis of Enamides using a Gold-Catalyzed Nucleophilic Addition to Allenamides. Org. Lett. 2010, 12, 1128-1131. For an example of regiocontrollable Pdcatalyzed hydroarylation of allenamides, see: (e) Cui, J.; Meng, L.; Chi, X.; Liu, Q.; Zhao, P.; Zhang, D.-P.; Chen, L.; Li, X.; Dong, Y. Liu, H. A Palladium-Catalyzed Regiocontrollable Hydroarylation Reaction of Allenamides With $\mathrm{B}_{2} \mathrm{pin}_{2} / \mathrm{H}_{2} \mathrm{O}$. Chem. Commun. 2019, $55,4355-4358$.

(5) (a) Cooper, L.; Alonso, J. M.; Eagling, L.; Newson, H.; Herath, S.; Thomson, C.; Lister, A.; Howsham, C.; Cox, B.; Muñoz, M. P. Synthesis of a Novel Type of 2,3'-BIMs via Platinum-Catalysed Reaction of Indolylallenes with Indoles. Chem. Eur. J. 2018, 24, 61056114. (b) Muñoz, M. P.; Torre, M. C.; Sierra, M. A. PlatinumCatalysed Bisindolylation of Allenes: A Complementary Alternative to Gold Catalysis. Chem. Eur. J. 2012, 18, 4499-4504. (c) Muñoz, M. P.; Torre, M. C.; Sierra, M. A. New Platinum-Catalysed Dihydroalkoxylation of Allenes. Adv. Sytn. Catal. 2010, 352, 2189-2194.

(6) Slater, N. H.; Brown, N. J.; Elsegood, M. R.; Kimber, M. C. The $\mathrm{Au}(\mathrm{I})$ Catalyzed Activation of Allenamides and Their Subsequent Transformation into Chromanes: A Method for the Regiocontrolled Addition to the $\alpha$ - and $\gamma$-Positions of the Allene Unit. Org. Lett. 2014, 16, 4606-4609.

(7) Menggenbateer; Narsireddy, M.; Ferrara, G.; Nishina, N.; Jin, T.; Yamamoto, Y. Gold-catalyzed regiospecific intermolecular hydrothiolation of allenes. Tetrahedron Lett. 2010, 51, 4627-4629.

(8) For selected examples, see: (a) Bliek, R.; Perego, L. A.; Ciofini, I.; Grimaud, L.; Taillefer, M.; Monnier, F. Copper-Catalysed Hydroamination of N-Allenylsulfonamides: The Key Role of Ancillary Coordinating Groups. Synthesis, 2019, 51, 1225-1234. (b) Perego, L. A;. Blieck, R.; Michel, J.; Ciofini, I.; Grimaud, L.; Taillefer, M.; Monnier, F. Copper-Catalyzed Hydroamination of N-Allenylazoles: Access to Amino-Substituted N-Vinylazoles. Adv. Synth. Catal. 2017, 359, 4388-4392. (c) Tafazolian, H.; Schmidt, J. A. R. Cationic $\left[(\text { Iminophosphine)Nickel(Allyl) }]^{+}\right.$Complexes as the First Example of Nickel Catalysts for Direct Hydroamination of Allenes. Chem. Eur. J. 2017, 23, 1507-1511. (d) Perego, L. A.; Blieck, R.; Groue, A.; Monnier, F.; Taillefer, M.; Ciofini, I.; Grimaud, L. Copper-Catalyzed Hydroamination of Allenes: from Mechanistic Understanding to Methodology Development. ACS Catal. 2017, 7, 4253-4264. (e) Novaes, L. F. T.; Pastre, J. C. Recent Advances on Hydroamination of Unsaturated Compounds. Quim. Nova 2017, 8, 932-945. (f) Blieck, R.; Bahri, J.; Taillefer, M.; Monnier, F. Copper-Catalyzed Hydroami- 
nation of Terminal Allenes. Org. Lett. 2016, 18, 1482-1485. (g) Butler, K. L.; Tragni, M.; Widenhoefer, R. A. Gold(I)-Catalyzed Stereoconvergent, Intermolecular Enantioselective Hydroamination of Allenes. Angew. Chem. Int. Ed. 2012, 51, 5175-5178.

(9) For selected examples on biological activity of azoles, see: (a) Jabir, N. R.; Firoz, C. K.; Bhushan, A.; Tabrez, S.; Kamal M. A. Azoles in Anticancer Research: Rational Approaches, Design Strategies, Recent Insights and Future Perspectives. Anti Cancer Agents in Medicinal Chemistry 2018, 18, 6-14. (b) Faria, J. V.; Vegi, P. F.; Miguita, A. G. C.; Santos, M. S.; Boechat, N.; Bernardino, A. M. R. Recently Reported Biological Activities of Pyrazole Compounds. Bioorg. Med. Chem. 2017, 25, 5891-5903. (c) Bhalla, A.; Bari, S. S.; Kumari, A. Recent Synthesis and Biological Applications of Novel Benzotriazoles: A Review. Am. J. PharmTech. Res. 2017, 7, 35-56. (d) Tardito, S.; Bassanetti, I.; Bignardi, C.; Elviti, L.; Tegoni, M.; Mucchino, C.; Bussolati, O.; Franchi-Gazzola, R.; Marchio, L. Copper Binding Agents Acting as Copper Ionophores Lead to Caspase Inhibition and Paraptotic Cell Death in Human Cancer Cells. J. Am. Chem. Soc. 2011, 133, 6235-6242. (e) Potapov, A. S.; Nudnova, E. A.; Domina, G. A.; Kirpotina, L. N.; Quinn, M. T.; Khlebnikov, A. I.; Schepetkin I. A. Synthesis, Characterization and Potent Superoxide Dismutaselike Activity of Novel Bis(pyrazole)-2,2'-bipyridyl Mixed Ligand Copper(II) Complexes. Dalton Trans. 2009, 4488-4498. (f) Ohlan, R.; Ohlan, S.; Judge, V.; Narang, R.; Ahuja, M.; Narasimhan, B. 2(2,4-Difluorophenyl)-1,3-bis(1,2,4-triazol-1-yl)propan-2-ol Derivatives: Synthesis, Antifungal Evaluation and QSAR Studies by Hansch Analysis. ARKIVOC 2007, xiv, 172-184.

(10) For selected examples of MOFs and metal complexes containing azoles in their structure, see: (a) Waller, P. J.; AlFaraj, Y. S.; Diercks, C. S.; Jarenwattananon, N. N.; Yaghi, O. M. Conversion of Imine to Oxazole and Thiazole Linkages in Covalent Organic Frameworks. J. Am. Chem. Soc. 2018, 140, 9099-9103. (b) Cardenal, A. D.; Park, H. J.; Chalker, C. J.; Ortiz, K. G.; Powers, D. C. Cis-Decalin Oxidation as a Stereochemical Probe of In-MOF Versus On-MOF Catalysis. Chem. Commun. 2017, 53, 7377-7380. (c) Zhao, Y.; Deng, D.-S.; Ma, L.-F.; Ji, B.-M.; Wang, L.-Y. A New Copper-Based Metal-Organic Framework as a Promising Heterogeneous Catalyst for Chemo- and Regioselective Enamination of $\beta$-Ketoesters. Chem. Commun. 2013, 49, 10299-10301. (d) Liu, B.; Yang, J.; Yang, G.-C.; Ma, J.-F. Four New Three-Dimensional Polyoxometalate-Based Metal-Organic Frameworks Constructed From $\left[\mathrm{Mo}_{6} \mathrm{O}_{18}\left(\mathrm{O}_{3} \mathrm{AsPh}\right)_{2}\right]^{4-}$ Polyoxoanions and Copper(I)-Organic Fragments: Syntheses, Structures, Electrochemistry, and Photocatalysis Properties. Inorg. Chem. 2013, 52, 84-94. (e) Yang, Y.; Du, P.; Yang, J.; Kan, W.-Q.; Ma, J.-F. A Series of $\mathrm{Cu}(\mathrm{II})$ and $\mathrm{Cd}(\mathrm{II})$ Coordination Polymers Constructed by 3,5-Dinitrosalicylic Acid and Flexible Bis(triazole) Ligands Containing Different Spacers. CrystEngComm 2013, 15, 4357-4371. (f) Jacobi, A.; Huttner, G.; Winterhalter, U.; Rhodium COD Complexes of Mixed Donor Set Tripod Ligands: Coordination Chemistry and Catalysis. J. Organomet. Chem. 1998, 571, 231-241.

(11) (a) Haydl, A. M.; Xu, K.; Breit, B. Regio- and Enantioselective Synthesis of $N$-Substituted Pyrazoles by Rhodium-Catalyzed Asymmetric Addition to Allenes. Angew. Chem. Int. Ed. 2015, 54, 7149-7153. (b) For an example with pyridones as nucleophiles, see: Li, C.; Kähny, M.; Breit, B. Rhodium-Catalyzed Chemo-, Regio-, and Enantioselective Addition of 2-Pyridones to Terminal Allenes. Angew. Chem. Int. Ed. 2014, 53, 13780-13784.

(12) Bernar, I.; Fiser, B.; Blanco-Ania, D.; Gomez-Bengoa, E.; Rutjes, F. P. J. T. Pd-Catalyzed Hydroamination of Alkoxyallenes with Azole Heterocycles: Examples and Mechanistic Proposal. Org. Lett. 2017, 19, 4211-4214.

(13) For reviews on bimetallic catalysis, see: (a) Farley C. M.; Uyeda, C. Organic Reactions Enabled by Catalytically Active MetalMetal Bonds. Trends in Chemistry 2019, 1, 497-509. (b) Powers, I. G.; Uyeda, C. Metal-Metal Bonds in Catalysis. ACS Catal. 2017, 7, 936-958. (c) Mankad, N. P. Selectivity Effects in Bimetallic Catalysis. Chem. Eur. J. 2016, 22, 5822-5829. (d) Perez-Temprano, M. H.; Casares, J. A.; Espinet, P. Bimetallic Catalysis using Transition and Group 11 Metals: An Emerging Tool for C-C Coupling and Other Reactions. Chem. Eur. J. 2012, 18, 1864-1884. (e) Allen, A. E.;
MacMillan, D. W. C. Synergistic catalysis: A powerful synthetic strategy for new reaction development. Chem. Sci. 2012, 3, 633-658.

(14) For selected examples on bimetallic catalysis involving gold, see: (a) Leyva-Pérez, A.; Doméenech-Carbó, A.; Corma, A. Unique distal size selectivity with a digold catalyst during alkyne homocoupling. Nat. Comm. 2015, 6, 6703. (b) Hashmi, A. S. K. Dual Gold Catalysis. Acc. Chem. Res. 2014, 47, 864-876. (c) Schmidbaurab, D. H.; Schier, A. Aurophilic interactions as a subject of current research: an up-date. Chem. Soc. Rev. 2012, 41, 370-412. (d) Hirner, J. J.; Shi, Y.; Blum, S. A. Organogold Reactivity with Palladium, Nickel, and Rhodium: Transmetalation, Cross-Coupling, and Dual Catalysis Acc. Chem. Res. 2011, 44, 603-613. (e) Hashmi, A. S. K.; Lothschütz, C.; Döpp, R.; Rudolph, M.; Ramamurthi, T. D.; Rominger, F. Gold and Palladium Combined for Cross-Coupling. Angew. Chem. Int. Ed. 2009, 48, 8243-8246.

(15) (a) García-Domínguez, P.; Nevado, C. Au-Pd Bimetallic Catalysis: The Importance of Anionic Ligands in Catalyst Speciation $J$. Am. Chem. Soc. 2016, 138, 3266-3269. (b) Al-Amin, M.; Roth, K. E.; Blum, S. A. Mechanistic Studies of Gold and Palladium Cooperative Dual-Catalytic Cross-Coupling Systems. ACS Catal. 2014, 4, 622629.

(16) (a) Alonso, J. M.; Muñoz, M. P. Heterobimetallic Catalysis: Platinum-Gold-Catalyzed Tandem Cyclization/C-X Coupling Reaction of (Hetero)Arylallenes with Nucleophiles. Angew. Chem. Int. Ed. 2018, 57, 4742-4746. (b) Alonso, J. M.; Muñoz, M. P. Evidence of Hybrid Homogeneous-Heterogeneous Catalysis in a Pt/Au Heterobimetallic System. Chem CatChem 2018, 10, 2646-2654.

(17) For an example of Au-catalyzed distal addition to alkoxyallenes, see: Wang, G.; Zou, Y.; Li, Z.; Wnag, Q.; Goeke, A. Cationic Gold(I)-Catalyzed Intermolecular [4+2] Cycloaddition between Dienes and Allenyl Ethers. Adv. Synth. Catal. 2011, 353, 550-556.

(18) For selected examples of unusual Au-catalyzed proximal additions to allenamides, see: (a) López, E.; González, J.; López, L. A. Unusual Regioselectivity in the Gold(I)-Catalyzed [3+2] Carbocycloaddition Reaction of Vinyldiazo Compounds and N-Allenamides. Adv. Synth. Catal. 2016, 358, 1428-1432. (b) Horino, Y.; Takata, Y.; Hashimoto, K.; Kuroda, S.; Kimura, M.; Tamaru, Y. Gold-Catalyzed Intermolecular Addition of Alcohols Toward the Allenic Bond of 4Vinylidene-2-oxazolidinones. Org. Biomol. Chem. 2008, 6, 41054107.

(19) Pt-allene complexes have shown to display a different coordination mode than $\mathrm{Au}$-allene ones in which the Pt atom is closer to the central atom of the allene, while the $\mathrm{Au}$ is closer to the terminal carbon. In activated allenes these differences could be emphasized by chelation effects of the Pt with the heteroatom, favoring the proximal addition. For Pt-allene complexes, see: Quiroś, M. T.; Muñoz, M. P.; Christensen, J.; Coles, S. J. Twists and Turns of Platinum-Allene Complexes: NMR Techniques for the Study of the Dynamic Behavior in Solution. Organometallics 2017, 36, 318-330. For Au-allene complexes, see: (a) Brown, T. J.; Sugie, A.; Dickens M. G.; Widenhoefer, R. A. Solid-State and Dynamic Solution Behavior of a Cationic, TwoCoordinate Gold(I) $\pi$-Allene Complex. Organomet. 2010, 29, 42074209. (b) Brown, T. J.; Sugie, A.; Leed, M. G. D.; Widenhoefer, R. A. Structures and Dynamic Solution Behavior of Cationic, TwoCoordinate Gold(I)- $\pi$-Allene Complexes. Chem. Eur. J. 2012, 18, 6959-6971.

(20) Schuitema, A. M.; Engelen, M.; Koval, I. A.; Gorter, S.; Driessen, W. L.; Reedijk. New Didentate Bispyrazole Ligands Forming Uncommon Eight-Ring Chelates with Divalent Copper, Zinc and Cobalt. J. Inorg. Chim. Acta 2001, 324, 57-64.

(21) Wang, Y.; Yi, L.; Yang, X.; Ding, B.; Cheng, P.; Liao, D.-Z.; Yan, S.-P. Synthesis, Crystal Structure, and Characterization of New Tetranuclear Ag(I) Complexes with Triazole Bridges. Inorg. Chem. 2006, 45, 5822-5829.

(22) See SI for details.

(23) For examples of phosphine-catalyzed distal addition of azoles to allenoates, see: (a) Wang, H.; Guo, C. Enantioselective $\gamma$-Addition of Pyrazole and Imidazole Heterocycles to Allenoates Catalyzed by Chiral Phosphine. Angew. Chem. Int. Ed. 2019, 58, 2854-2858. (b) Virieux, D.; Guillouzic, A.-F.; Cristau, H.-J. Phosphines Catalyzed 
Nucleophilic Addition of Azoles to Allenes: Synthesis of Allylazoles and Indolizines. Tetrahedron 2006, 62, 3710-3720.

(24) (a) Khrakovsky, D. A.; Tao, C.; Johnson, M. W.; Thornbury, R. T.; Shevick, S. L.; Toste, F. D. Enantioselective, Stereodivergent Hydroazidation and Hydroamination of Allenes Catalyzed by Acyclic Diaminocarbene (ADC) Gold(I) Complexes. Angew. Chem. Int. Ed. 2016, 55, 6079-6083. (b) Wang, Z. J.; Benitez, D.; Tkatchouk, E.; Goddard III, W. A.; Toste, F. D. Mechanistic Study of Gold(I)Catalyzed Intermolecular Hydroamination of Allenes. J. Am. Chem. Soc. 2010, 132, 13064-13071. It is worth noting that during our studies on gold-catalyzed azidation of allenes, we observed isomerization between regioisomeric allyl azides. See: (c) Hurtado-Rodrigo, C.; Hoehne, S. Muñoz, M. P. A New Gold-Catalysed Azidation of Allenes. Chem. Commun. 2014, 50, 1494-1496.

(25) Kinjo, R.; Donnadieu, B.; Bertrand; G. Gold-Catalyzed Hydroamination of Alkynes and Allenes with Parent Hydrazine. Angew. Chem. Int. Ed. 2011, 50, 5560-5563.

(26) The Pd- and Rh-catalyzed additions are proposed to occur via intermolecular attack of the azole to the more substituted carbon in $\pi$ allyl metallic intermediates to give adducts 3 . Although this type of intermediate could be also involved in the $\mathbf{3} \rightarrow \mathbf{2}$ isomerization in our case, they are less common intermediates in $\mathrm{Au}$ and Pt catalysis.

(27) (a) Muñoz-Lopez, S.; Couce-Rios, A.; Sciortino, G.; Lledos, A.; Ujaque, G. Mechanistic Insights on the Hydration of Terminal and Internal Allenes Catalyzed by [(NHC)Au $]^{+}$. Organometallics 2018, 37, 3543-3551. (b) Paton, R. S.; Maseras, F. Gold(I)-Catalyzed Intermolecular Hydroalkoxylation of Allenes: A DFT study. Org. Lett. 2009, 11, 2237-2240. For the experimental evidence on this isomerization in the reaction with alcohols, see: (c) Webster, S.; Sutherland, D.; Lee, A.-L. Chirality Transfer in Gold(I)-Catalysed Hydroalkoxylation of 1,3-Disubstituted Allenes. Chem. Eur. J. 2016, 22, $18593-$ 18600. (d) Baker, G.; Johnson, D. G.; Young, P. C. Macgregor, S. A.; Lee, A.-L. Chirality Transfer in Gold(I)-Catalysed Direct Allylic Etherifications of Unactivated Alcohols: Experimental and Computational Study. Chem. Eur. J. 2015, 21, 13748-13757. (e) Hadfield, M. S.; Lee, A.-L. Regioselective Synthesis of tert-Allylic Ethers via Gold(I)-Catalyzed Intermolecular Hydroalkoxylation of Allenes. Org. Lett. 2010, 12, 484-487.
(28) We have observed a similar protodemetallation of Pt-Csp species and the final reductive elimination, to be the rate limiting step in the Pt-catalyzed dihydroalkoxylation of allenes, in which metal coordinated vinyl ethers of the type $\mathbf{C} \leftarrow \rightarrow \mathbf{C}^{\prime}$ are resting states on the reaction. Quirós, M. T.; Gómez-Bengoa, E.; Muñoz, M. P. unpublished.

(29) The reaction of allenamides in the presence of phenols catalyzed by $\mathrm{Tf}_{2} \mathrm{NH}$ has been reported to give chromanes by 1,3-double addition, see: Hashimoto, K.; Horino, Y.; Kuroda, S. Synhtesis of Functionalized Chromanes via Formal [3+3] Cycloaddition of Allene Sulfonamides to Phenols. Heterocycles, 2010, 80, 187-198.

(30) Albeniz, A. C.; Espinet, P.; Fernandez, R. L.; Sen, A. A Warning on the Use of Radical Traps as a Test for Radical Mechanisms: They React with Palladium Hydrido Complexes. J. Am. Chem. Soc. 2002, 124, 11278-11279.

(31) (a) Haidasz, E. A.; Meng, D.; Amorati, R.; Baschieri, A.; Ingold, K. U.; Valgimigli, L.; Pratt, D. A. Acid Is Key to the RadicalTrapping Antioxidant Activity of Nitroxides. J. Am. Chem. Soc. 2016, 138, 5290-5298. (b) Sen', V. D.; Golubev, V. A. Kinetics and Mechanism for Acid-Catalyzed Disproportionation of 2,2,6,6Tetramethylpiperidine-1-oxyl. J. Phys. Org. Chem. 2009, 22 138143. (c) Nosova, K. E.; Tretyakov, E. V.; Romanenko, G. V.; Ovcharenko, V. I. Reaction Products of Nitronyl Nitroxyl Radicals with acids. Russ. Chem. bull Int. Ed. 2003, 52, 2231-2234).

(32) For a review on gold-hydrides, see: (a) Schmidbaur, H.; Raubenheimer, H. G.; Dobrzanska, L. The Gold-Hydrogen Bond, $\mathrm{Au}-\mathrm{H}$, and the Hydrogen Bond to Gold, Au- $\cdots \mathrm{H}-\mathrm{X}$. Chem. Soc. Rev. 2014, 43, 345-380. For a recent example of $\mathrm{Au}(\mathrm{III})$ hydrides, see: (b) Rocchigiani, L.; Fernandez-Cestau, J.; Chambrier, I.; Hrobarik, P.; Bochmann, M. Unlocking Structural Diversity in Gold(III) Hydrides: Unexpected Interplay of cis/trans-Influence on Stability, Insertion Chemistry, and NMR Chemical Shifts. J. Am. Chem. Soc. 2018, 140, 8287-8302.

(33) (a) Hicken, A.; White, A. J. P.; Crimmin, M. R. Selective Reduction of $\mathrm{CO}_{2}$ to a Formate Equivalent with Heterobimetallic Gold- -Copper Hydride Complexes. Angew. Chem. Int. Ed. 2017, 56, 15127-15130. (b) Lehner, H.; Matt, D.; Pregosin, P. S.; Venanzi, L. M. Stable Gold Hydride Complexes. J. Am. Chem. Soc. 1982, 104, 6827-6828. 